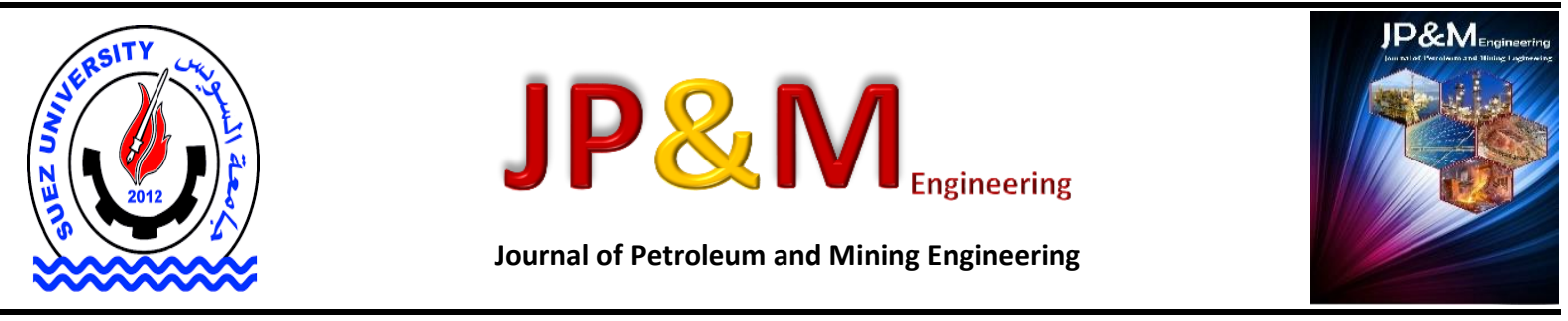

\title{
A Review on Natural Gas Previous, Current and Forecasting Prices and Demand
}

\author{
Abdallah S. Elgharbawy \\ a Materials Science Department, Institute of Graduate Studies and Research (IGSR), Alexandria University, 163 Horrya Avenue, P.O. Box \\ 832, Shatby , 21526 Alexandria, Egypt. \\ *ab_pet88@hotmail.com
}

\section{Article Info \\ Received 6 Apr. 2020 Revised 30 May 2020 Accepted 2 Jun. 2020}

\section{Keywords}

Natural gas; price;demand

\begin{abstract}
The significance of natural gas appears as a competitive substitute for crude oil. Therefore, for many years, fuel switching between natural gas and crude oil made natural gas prices closely aligned with crude oil. On the other hand, the price of natural gas for end-users varies greatly across Europe, Asia, and Africa. There was an upward trend in energy commodity prices since 2000 , but with the surge in supply coming from unconventional oil and gas resources in North America, the trend in natural gas prices has become downward in recent years due to the many reasons. This paper examines and investigates the global market of natural gas including previous, current, and future prices and demand. Additionally, it shows the effect of political and economic issues on natural gas prices and demand during the period from 2014 to 2020. The paper shows and interprets the expectations of the natural gas market until 2040.
\end{abstract}

\section{Introduction}

Natural gas is a naturally occurring hydrocarbon mixture that mainly consists of methane, but usually includes varying amounts of other higher alkanes, sometimes a small percentage of carbon dioxide, nitrogen, and hydrogen sulphide ${ }^{[1]}$. In addition to the use of natural gas in electricity generation, natural gas consumption increases in the industrial sector. Chemical and primary metals manufacturing, as well as oil and natural gas extraction, account for most of the growing industrial demand ${ }^{[2]}$. Besides, a decline in the energy intensity of economies across geographies offsets the increase in energy demand needed to support a growing population with increasing income levels, especially in emerging markets.

Natural gas is the only fossil fuel which grows its share of total energy demand until the year 2035, even though at declining growth rates, natural gas demand remains robust within $a+/-3$ percent range ${ }^{[3]}$. It is expected that global natural gas consumption increases more than 40 percent between the year 2018 and the year 2050, and total consumption reaches nearly 200 quadrillions Btu by the year 2050 . We should understand the driving factors of natural gas pricing as it is crucial for both market investors and policy makers ${ }^{[4]}$. The expansion of shale gas production in the United States has caused prices to drop relative to other countries, especially Europe and Asia, leaving natural gas in the United States three times cheaper ${ }^{[5]}$. Currently, Europe's main natural gas supplier is Russia. The main pipelines pass through Ukraine and there have been several disputes on the supply and transition prices between Ukraine and Russia. At the end of 2013, the government in Ukraine was changed, Russia's military interferes in Ukraine's result to the annexation of Crimea in March 2014 ${ }^{[5,6]}$. The EU stands against this unexpected behaviour of Russia and the political crisis appears between Russia and the EU. Russia supplies $30 \%$ of natural gas to Europe half it through Ukraine ${ }^{[7]}$. This crisis has had many effects as gas supplies to Europe stopped. In 2020, Natural gas spot prices fell at most locations from $\$ 2.5$ per million British thermal units (MMBtu) to $\$ 1.9 / \mathrm{MMBtu}^{[8-10]}$.

\section{Discussion}

\subsection{Natural Gas previous, current and forecasting Prices}

Natural gas in 2015 and 2016 exhibited a sudden and unexpected decrease in pricing as shown in figure 1 compared to the prices of 2013 and 2014 as the price of $1 \mathrm{MMBtu}$ reached $2 \$$ and prices staying low until 2017. Analysts concluded that there were many reasons for this drop summarized in the next part ${ }^{[11]}$.

- Full natural gas storage sites slowed the potential rebound of natural gas prices, as it would put a dampener on demand shortly[12, 13].

- Europe began to import liquefied natural gas from the U.S to lessen dependency on Russian gas since the US had become 
the number one producer of natural $\operatorname{gas}^{[12,14]}$.

- The dispute between Ukraine and Russia cut off the gas to Europe as gas imported the Russian gas from the pipeline passing through Ukraine. This situation encouraged the US to invade the European market and sunk the market with a cheap gas price ${ }^{[15]}$.

- Many explorations of cheap shale oil and shale gas encourage the natural gas supplier to decrease prices ${ }^{[5]}$.

- Saudi Arabia's actions contributed to the falling of oil prices in 2014 and this leaded to a sharp decrease in natural gas prices $^{[16]}$.

Figure 1 shows that in 2017, a considerable rise in gas price occurred as the price of $1 \mathrm{MMBtu}$ grew up to 3.5 \$. The prices between 2017 and 2018 exhibit moderate fluctuations as the price ranged from 3.6 to $2.6 \$$ for 1 MMBtu. At the mid of 2018, a dramatic increase in gas price happened and the price of 1 MMBtu reached 4.8 . The reason for this increase was due to relatively low levels of natural gas in storage, an increase in oil prices, and a sharp decline in dollar value. In 2019, a decrease in natural gas prices occurred because the new gas reserves entered the service and the abundant stores of natural gas.

In 2020, a great fall down in gas prices achieved due to the catastrophic spread of Coronavirus and its impact on the global economy other than the rapid depression of oil prices. The price of $1 \mathrm{MMBtu}$ lessened from $3 \$$ at the beginning of 2019 to 2.5 at the beginning of 2020. Currently, it reached to $1.6 \$$ for $1 \mathrm{MMBtu}$.

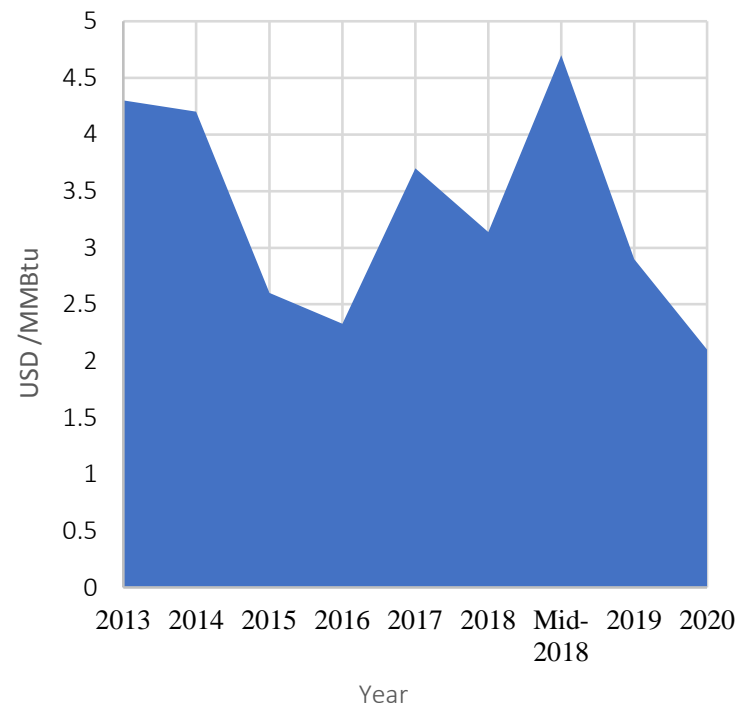

Figure 1: Natural Gas Prices within the last 8 years ${ }^{[17,18]}$

Table 1 shows the forecasting price of natural gas as per the outlook of World Bank. For the expected gas price in next five prices, it is proposed that gas prices will increase gradually to reach $2.5 \$ / \mathrm{MMbtu}$ at the end of 2020 in USA and $6.7 \$ / M M b t u$ in japan. The prices are expected to be almost steady for the next four years in all regions. This means that natural gas as a standalone product will not be a profitable product. It is seen that that prices in Japan and Europe is duplicated that that of USA due to the high cost of transportation of liquefied gas from the USA to Europe and Japan. For Japan, prices are higher than Europe due to farther distance.

Table 1: Expected gas price for the next 5 years in different countries ${ }^{[17,18]}$

\begin{tabular}{|c|c|c|c|c|c|}
\hline Region & 2020 & 2021 & 2022 & 2023 & 2024 \\
\hline USA & 2.5 & 2.57 & 2.5 & 2.57 & 2.6 \\
\hline E.U & 6 & 6 & 5.8 & 5.72 & 5.67 \\
\hline Japan & 6.7 & 6.7 & 6.7 & 6.7 & 6.7 \\
\hline
\end{tabular}

\subsection{Natural Gas previous, current and forecasting demand}

Currently, the world consumes around 4000 billion cubic meters of natural gas per year. As per region, North America and Europe currently are the most consumers of global natural gas with $28 \%$ and $16 \%$ respectively while the Middle East consumes only $12 \%$. For countries, the USA and Russia consume about 22 and $14 \%$ of global natural gas production. Far from these countries, China occupies the third rank as it consumes $5.5 \%$ of global production but China is expected to be the first gas consumer in the next 20 years and become the most crucial player in the natural gas market. This is due to the massive development in Chinese industries and manufacturing based on natural gas. Figure 2 displays two scenarios for the global natural gas demand from 2018 to 2024 [19-21].

As per the first scenario in figure 2, the highest natural gas consumption in 2018 was for North America, Europe, and Asia. This scenario expected that in $\mathbf{2 0 3 0}$ the gas consumption of Europe would be almost steady. Whereas, Asia's consumption will exhibit a noticeable rise. Additionally, there will be a slight increase in North America consumption. In 2040, the consumption of Asia would boom dramatically as its gas consumption would be around 1.7 billion $\mathrm{m}^{3} /$ year. The gas consumption of North America in 2040 compared to that in 2030 would be the same. On the contrary, Europe's dependency on natural gas would decrease in 2040 compared to its consumption in 2030 and 2018. This is because the plans in Europe depend on renewable energy such as biofuels, solar, and wind energy. It is noted that the Middle East consumption of natural gas would increase in 2040 than in 2018. Generally, this scenario expected a gradual increase in global gas consumption from 4000 billion $\mathrm{m}^{3} /$ year in 2018 up to 5500 billion $\mathrm{m} 3 /$ year in $2040^{[19,22,23]}$.

According to the second scenario in figure 2, the highest natural gas consumption in 2018 was for 
North America, Europe, and Asia which was the same as in the first scenario. This scenario expected that in 2030 the gas consumption of Europe would decrease. In contrast, Asia's consumption will exhibit a noticeable rise. Besides, there would be a steady-state in North America gas consumption. In 2040, the consumption of Asia would continue its increase in consumption and would be around 1.5 billion $\mathrm{m}^{3} /$ year. The gas consumption of North America in 2040 compared to that in 2030 would decrease. Moreover, Europe's dependency on natural gas would decrease in 2040 compared to its consumption in 2030 and 2018. It is noted that the Middle East consumption of natural gas would decrease in 2040 than in 2018. Generally, this scenario expected a gradual decrease in global gas consumption from 4000 billion m3/year in 2018 up to 3900 billion $\mathrm{m}^{3} /$ year in $2040^{[18,24]}$.

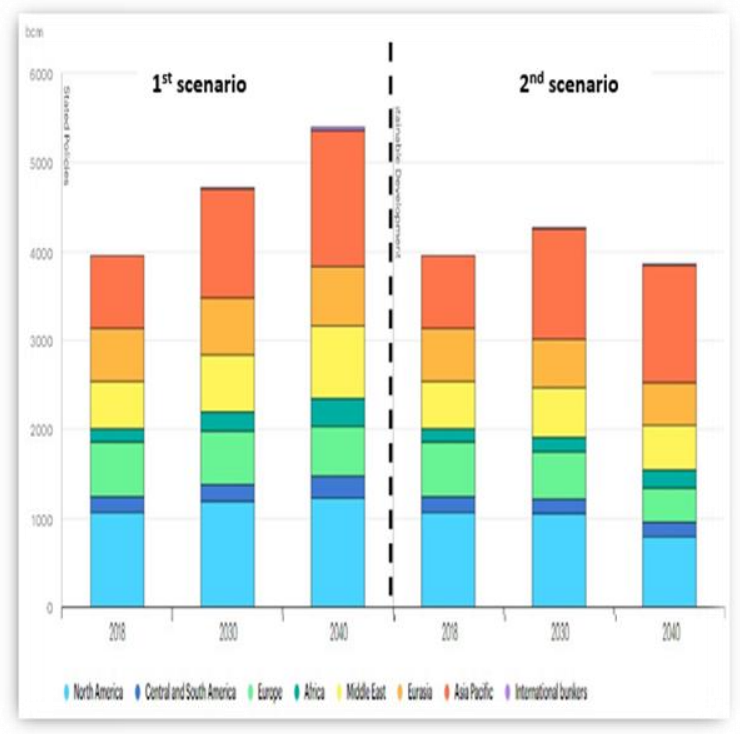

Figure 2: Scenarios of Gas demand by region from 2018 to $2040[18,24]$

Figure 3 shows the growth in global gas consumption in 6 years from 2018 to 2014 . The figure also shows the sectors that consume gas. It is obvious the enormous increase in Chinese gas consumption by 170 billion cubic meters in only 6 years. The most sector in China that consumes gas is the industrial sector and building due to the massive population of China. The Middle East comes in the second rank by an increase of about 70 billion cubic meters in 6 years. The US dependency on natural gas grows by 40 billion cubic meters in all sectors. On the contrary, Europe will lessen its dependency on gas in the domestic sector while in the industrial sector growth will exist with a little increase. Japan will decrease its dependency on gas in power generation as it depends on nuclear energy in generating electricity while for the demotic sector a small increase in gas consumption ${ }^{[18,24]}$.

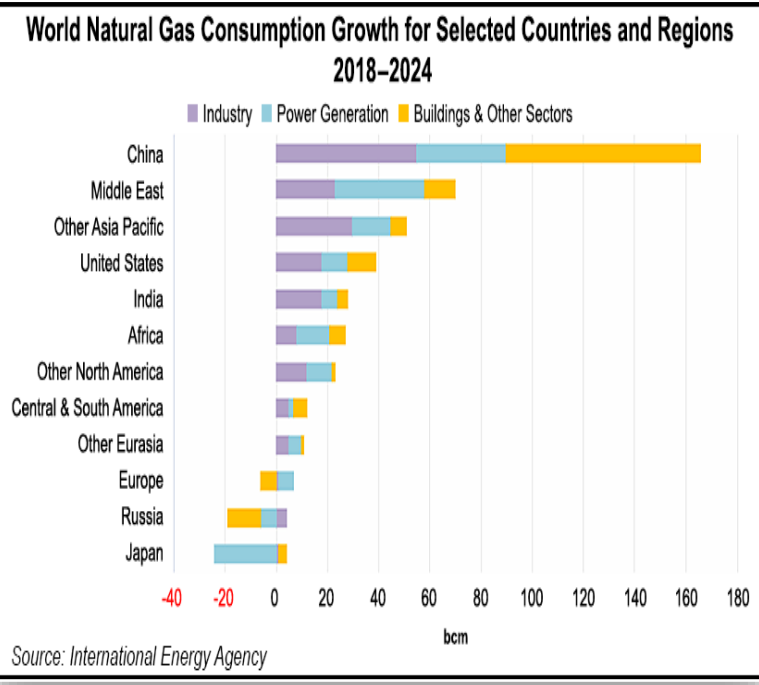

Figure 3: Global natural gas consumption growth by region $[17,18,24]$

\section{Conclusion}

The natural gas market either prices or demand exhibited fluctuation in the last five years. This fluctuation in prices and demand is still existing due to the spread of coronavirus and its destructive effect on the global economy. We concluded that the gas market is beyond expectation as there are many factors affect it. Political and economic issues have a great effect on the market. Besides, shale gas and shale oil also play an essential role in affecting the gas market. Some countries tend to store large quantities of gas and this contributes to the market fluctuations. Finally, the crude oil price has a noticeable influence on the market. China will be the player maker in the gas market in the next decades in parallel with a fall back of Europe and America in the gas market. The industrial sector boom in China will be the reason for that. Also, the plans in Europe to reduce the utilization of fossil fuel and their intention to substitute renewable energy.

In my opinion, natural gas is a cheap resource of energy and it is a valuable product that must be directed to profitable industries such as petrochemical or fertilizers as it will be more useful and add-value for natural gas. Moreover, products of petrochemical or fertilizers have high and stable prices not fluctuated prices such as natural gas.

\section{Conflicts of interest}

There are no conflicts to declare.

\section{References:}

1.

Faramawy, S., T. Zaki, and A.-E. Sakr, Natural gas origin, composition, and processing: A review. Journal of Natural Gas Science and Engineering, 2016. 34: p. 34-54. 
2. Lin, J., et al., Has coal use peaked in China: Nearterm trends in China's coal consumption. Energy policy, 2018. 123: p. 208-214.

3. Gielen, D., et al., The role of renewable energy in the global energy transformation. Energy Strategy Reviews, 2019. 24: p. 38-50.

4. Sieminski, A., International energy outlook. Energy information administration (EIA), 2014. 18.

5. Wang, Q., et al., Natural gas from shale formation-the evolution, evidences and challenges of shale gas revolution in United States. Renewable and Sustainable Energy Reviews, 2014. 30: p. 1-28.

6. Bērziňš, J., Russia's new generation warfare in Ukraine: Implications for Latvian Defense Policy. Policy Paper, 2014. 2: p. 2002-2014.

7. Hasan, M.A., K.M. Nahiduzzaman, and A.S. Aldosary, Public participation in EIA: $A$ comparative study of the projects run by government and non-governmental organizations. Environmental Impact Assessment Review, 2018. 72: p. 12-24.

8. Herranz-Surrallés, A., I. Solorio, and J. Fairbrass, Renegotiating authority in the Energy Union: A Framework for Analysis. Journal of European Integration, 2020. 42(1): p. 1-17.

9. Bartelet, H. and M. Mulder, Natural Gas markets in the European Union: Testing Resilience. Economics of Energy \& Environmental Policy, 2020. 9(1).

10. Anisah, P. and E. Agustian. Effect of transesterification on the result of waste cooking oil conversion to biodiesel. in Journal of Physics: Conference Series. 2019. IOP Publishing.

11. Monge, M. and L.A. Gil-Alana, Fractional integration and cointegration in merger and acquisitions in the US petroleum industry. Applied Economics Letters, 2016. 23(10): p. 701704.

12. Engerer, H. and M. Horn, Natural gas vehicles: An option for Europe. Energy Policy, 2010. 38(2): p. 1017-1029.

13. Barysch, K., Russia, realism and EU unity. 2007.

14. Koch, N., et al., Causes of the EU ETS price drop: Recession, CDM, renewable policies or a bit of everything?-New evidence. Energy Policy, 2014. 73: p. 676-685.

15. Siddi, M., Identities and vulnerabilities: The Ukraine crisis and the securitisation of the EURussia gas trade, in Energy Security in Europe. 2018, Springer. p. 251-273.

16. Guesmi, K. and S. Fattoum, Return and volatility transmission between oil prices and oilexporting and oil-importing countries. Economic Modelling, 2014. 38: p. 305-310.

17. Center, B.P., Annual Energy Outlook 2020. 2020.

18. None, N., Annual Energy Outlook 2016 With Projections to 2040. 2016, USDOE Energy Information Administration (EI), Washington, DC (United States ....

19. BANK, W., Middle East and North Africa Economic Developments and Prospects, October 2012: Looking Ahead After a Year in Transition. 2012: World Bank Publications.

20. Hoornweg, D. and M. Freire, Building sustainability in an urbanizing world: $A$ partnership report. 2013.
21. Zhang, D., M. Shi, and X. Shi, Oil indexation, market fundamentals, and natural gas prices: An investigation of the Asian premium in natural gas trade. Energy Economics, 2018. 69: p. 33-41.

22. Cabalu, H., Indicators of security of natural gas supply in Asia. Energy Policy, 2010. 38(1): p. 218225.

23. Tarr, D.G., Export restraints on russian natural gas and raw timber: what are the economic impacts? 2010: The World Bank.

24. Newell, R., D. Raimi, and G. Aldana, Global Energy Outlook 2019: The Next Generation of Energy. 2019, Report. 